\title{
Overexpression of interleukin-32 $\alpha$ promotes invasion by modulating VEGF in hepatocellular carcinoma
}

\author{
WEN-BO ZHAO ${ }^{1}$, QUAN-LI WANG $^{2,4}$, YAN-TIAN XU ${ }^{3}$, SHI-FENG XU ${ }^{3}$, YANG QIU ${ }^{1}$ and FENG ZHU ${ }^{4}$ \\ ${ }^{1}$ Department of Hematology, Shandong Provincial Hospital Affiliated to Shandong University, Jinan, Shandong 250021; \\ ${ }^{2}$ Department of Traditional Chinese Medicine, County People's Hospital of Wulian, Rizhao, Shandong 262300; \\ ${ }^{3}$ Department of Hepatobiliary Surgery, Shandong Provincial Hospital Affiliated to Shandong University, \\ Jinan, Shandong 250021; ${ }^{4}$ Department of Hematology and Oncology, Affiliated Hospital of \\ Taishan Medical University, Taian, Shandong 27100, P.R. China
}

Received September 12, 2016; Accepted September 27, 2017

DOI: 10.3892/or.2017.6162

\begin{abstract}
Interleukin-32 $\alpha$ (IL-32 $\alpha$ ) was reported to exhibit pluripotent pro-inflammatory properties. Recent studies indicate that it promotes the migration and invasion of cancers. We detected the expression of IL-32 in hepatocellular carcinoma (HCC) tissues and investigated its role in tumor angiogenesis and invasion. IL-32 $\alpha$ expression in HCC was evaluated by realtime PCR, western blot analysis and immunohistochemical (IHC) staining. Secreted serum IL-32 $\alpha$ and VEGF concentrations were detected using a custom-made sandwich ELISA. Furthermore, IL-32 $\alpha$ was knocked down in HCC cell lines using siRNA and the cell migration and invasion abilities were assessed. IHC staining showed that IL32 $\alpha$-positive particles were mainly located in the cytoplasm of cancer cells, and it was significantly upregulated in the tumor tissues compared with that in peritumoral tissues. Notably, IL-32 $\alpha$ was strongly expressed in perivascular areas. The mean serum concentration of IL-32 $\alpha$ in HCC patients was significantly higher than that in the control group $(571.45 \pm 102.28$ vs. $144.60 \pm 51.172 \mathrm{pg} / \mathrm{ml}$; $\mathrm{P}<0.01)$. Real-time RT-PCR showed that IL-32 $\alpha$ mRNA was significantly overexpressed in HCC tumor tissues (IL-32/ $\beta$ actin, $15.59 \pm 7.8$ vs. $3.37 \pm 0.47 ; \mathrm{P}<0.01)$. The in vitro results indicated that IL-32 $\alpha$ knockdown inhibited the activation of VEGF-STAT3 signaling in HCC tumor cell lines. IL-32 $\alpha$ expression was correlated with clinical relevance in HCC tumor tissues. It is strongly suggested that IL-32 $\alpha$ may be a potential predictor of anti-angiogenesis therapy and prognosis of HCC.
\end{abstract}

Correspondence to: Dr Feng Zhu, Department of Hematology and Oncology, Affiliated Hospital of Taishan Medical University, 706 Taishan Street, Taian, Shandong 27100, P.R. China

E-mail: fengzhu2006@126.com

Abbreviations: HCC, hepatocellular carcinoma; IHC, immunohistochemistry; IL-32, interleukin-32; NK, natural killer; VEGF vascular endothelial growth factor; DMEM, Dulbecco's modified Eagle's medium; FBS, fetal bovine serum; ELISA, enzyme-linked immununosorbent assay

Key words: hepatocellular carcinoma, IL-32 $\alpha$, VEGF, angiogenesis

\section{Introduction}

Hepatocellular carcinoma (HCC) is one of the most common cancers worldwide and the third most common cause of cancer-related death $(1,2)$. It is particularly prevalent in Asia and sub-Saharan Africa countries $(3,4)$. A progressive increase in HCC-related mortality has been observed in the US and Western Europe (5-7). Accumulating evidence has revealed that inflammatory-related cytokines participate in the carcinogenesis and progression of HCC (8). Research has revealed that higher expression of interleukin-32 (IL-32), a novel pro-inflammatory cytokine, is detected in HCC (9). However, the potential roles of IL-32 in the carcinogenesis and progression of $\mathrm{HCC}$ remain unclear.

IL-32, originally called natural killer (NK) cell transcript 4, is a recently described cytokine that is mainly produced by T, NK and epithelial cells after stimulation $(10,11)$. Six splice variants have been reported in the IL-32 family, including

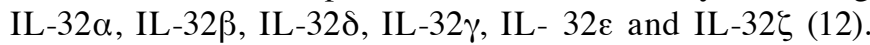
Besides its pluripotent pro-inflammatory properties, it has been unambiguously shown that IL-32 $\alpha$ enhances the migration and invasion of cancers, such as breast cancer, gastric cancer and lung cancer (13-15). However, the function and role of IL-32 $\alpha$ in HCC progression remain unknown.

The present study explored the expression of IL- $32 \alpha$ in $\mathrm{HCC}$ and its role in vascular invasion and tumor progression. Mechanistic investigation was conducted to show the potential downstream factor in the IL-32 signaling pathway. The results suggested a specific mechanism of IL-32 in HCC and present a potential therapeutic target for HCC treatment and drug development.

\section{Materials and methods}

Patients and tissue specimens. Tumor tissues and paired noncancerous hepatic parenchyma were collected from 100 patients with primary $\mathrm{HCC}$ who received surgical resection from May 2010 to June 2011 at the Department of Hepatobiliary Surgery, Shandong Provincial Hospital Affiliated to Shandong University. Serum specimens were collected from the patients and 30 control patients without HCC. None of the patients had 
received preoperative chemotherapy or other treatment before surgery. Patient written informed consent was obtained, and the study protocol was approved by the Health Service Ethics Committee of Shandong Provincial Hospital Affiliated to Shandong University. HCC was histologically diagnosed by two pathologists independently and the clinical characteristics of each patient were recorded as shown in Table I.

Ethical approval. The present study was performed in accordance with the Declaration of Helsinki and approved by the local Ethics Committee. All patients provided their informed consent.

Quantitative real-time RT-PCR. Fresh HCC tissues were treated with TRIzol reagent for total RNA extraction (Invitrogen Carlsbad, CA, USA) and purified by phenol/ $\mathrm{CHCl}_{3}$ according to the manufacturer's instructions. Total RNA (5 $\mu \mathrm{g})$ was reversely transcribed to cDNA using the MBI Fermantas reverse transcription kit (MBI Fermentas, Vilnius, Lithuania). The Quantitative SYBR-Green PCR kit and ABI Prism 7000 Sequence Detection System (both from ABI, USA) were applied to test the expression level of IL-32 $\alpha$ under the following conditions: 30 cycles: 1 cycle at $95^{\circ} \mathrm{C}$ for $5 \mathrm{~min}$, then 30 cycles at $94^{\circ} \mathrm{C}$ for $30 \mathrm{sec}$ and $60^{\circ} \mathrm{C}$ for $45 \mathrm{sec}$; quantitative RT-PCR was repeated at least 3 times. $\beta$-actin expression was used for normalization. Primer sequences are listed as follows: IL-32 $\alpha$ F, 5'-ACAGTGGCGGCTTATTATGAGGA-3' and R, 5'-GTTGCCTCGGCACCGTAATC-3'; $\beta$-actin F, 5'-AATGC TTCTAGGCGGACTATGA-3' and R, 5'-CAAGAAAGGGT GTAACGCAACT-3'.

Western blotting. Five fresh HCC and paired non-cancerous tissues were lysed by cold RIPA buffer containing protease inhibitor on ice for $30 \mathrm{~min}$, and centrifuged at $12,000 \mathrm{xg}$ at $4^{\circ} \mathrm{C}$ for $20 \mathrm{~min}$. The protein concentration was determined using a BCA protein assay kit (Biocolor Biotech, Shanghai, China). Proteins suspended in loading buffer were denatured and separated using $10 \%$ sodium dodecyl sulfate-polyacrylamide gel electrophoresis (SDS-PAGE) and electrophoretically transferred onto a polyvinylidene difluoride (PVDF) membrane (Millipore, Bedford, MA, USA) in transfer buffer at $40 \mathrm{~V}$ for $105 \mathrm{~min}$. The membrane was blocked using 5\% skimmed milk in Tris-buffered saline with Tween-20 (TBST) for $2 \mathrm{~h}$, washed with TBST and incubated with mouse anti-IL-32 antibody (R\&D Systems, Minneapolis, MN, USA) overnight at $4^{\circ} \mathrm{C}$. The membrane was incubated with an anti-mouse horseradish peroxidase-conjugated secondary antibody (Dako, Glostrup, Denmark) at a dilution of 1:200 at room temperature for $1 \mathrm{~h}$. Protein bands were visualized by SuperSignal West Pico Chemiluminescent Substrate kit (Pierce, Rockford, IL, USA) and exposed using Kodak X-ray film (Kodak, Rochester, NY, USA). Proteins were re-blotted with anti-GAPDH (Zymed, South San Francisco, CA, USA) as an internal control.

Immunohistochemical staining. For immunohistochemical analysis, $4-\mu \mathrm{m}$ tissue sections were cut from paraffin blocks and baked at $60^{\circ} \mathrm{C}$ for $2 \mathrm{~h}$ before staining with mouse antiIL-32 $\alpha$ antibody (dilution 1:100; R\&D Systems). Endogenous peroxidase activity was blocked with $3 \% \mathrm{H}_{2} \mathrm{O}_{2}$ for $30 \mathrm{~min}$. Then tissue sections were pre-treated in citrate buffer using
Table I. Correlations between serum IL-32 expression and clinicopathological parameters in 100 patients with HCC.

\begin{tabular}{|c|c|c|c|}
\hline $\begin{array}{l}\text { Clinicopathological } \\
\text { parameters }\end{array}$ & Cases & $\begin{array}{c}\mathrm{T} / \mathrm{N}^{\mathrm{a}} \\
(\text { mean } \pm \mathrm{SE})\end{array}$ & P-value \\
\hline Age (years) & & & $0.312^{\mathrm{b}}$ \\
\hline$<60$ & 72 & $16.49 \pm 9.10$ & \\
\hline$\geq 60$ & 28 & $13.50 \pm 3.03$ & \\
\hline Sex & & & $0.184^{\mathrm{b}}$ \\
\hline Male & 80 & $15.78 \pm 4.88$ & \\
\hline Female & 20 & $13.56 \pm 3.20$ & \\
\hline \multicolumn{4}{|l|}{ Virus } \\
\hline $\mathrm{HBV}$ & 54 & $14.48 \pm 3.56$ & $0.271^{\mathrm{c}}$ \\
\hline $\mathrm{HCV}$ & 6 & $14.31 \pm 4.96$ & \\
\hline None & 40 & $16.64 \pm 5.72$ & \\
\hline $\mathrm{AFP}(\mathrm{ng} / \mathrm{ml})$ & & & $0.157^{\mathrm{b}}$ \\
\hline$<20$ & 30 & $13.89 \pm 3.33$ & \\
\hline$\geq 20$ & 70 & $15.96 \pm 5.02$ & \\
\hline Tumor multiplicity & & & $0.249^{\mathrm{b}}$ \\
\hline Single & 90 & $15.07 \pm 4.70$ & \\
\hline Multiple & 10 & $17.69 \pm 3.72$ & \\
\hline Tumor size $(\mathrm{cm})$ & & & $0.460^{\mathrm{b}}$ \\
\hline$<3.5$ & 46 & $14.80 \pm 4.03$ & \\
\hline$\geq 3.5$ & 54 & $15.79 \pm 5.15$ & \\
\hline Differentiation & & & $0.798^{c}$ \\
\hline Well & 16 & $14.42 \pm 3.45$ & \\
\hline Moderate & 60 & $15.35 \pm 5.10$ & \\
\hline Poor & 24 & $15.91 \pm 4.35$ & \\
\hline Liver cirrhosis & & & $0.811^{\mathrm{b}}$ \\
\hline Yes & 40 & $15.14 \pm 3.95$ & \\
\hline No & 60 & $15.47 \pm 5.12$ & \\
\hline Vascular invasion & & & 0.007 \\
\hline Yes & 18 & $19.05 \pm 5.99^{\mathrm{b}}$ & \\
\hline No & 82 & $14.52 \pm 3.94$ & \\
\hline Metastasis & & & $0.011^{\mathrm{b}}$ \\
\hline Yes & 24 & $18.26 \pm 5.85$ & \\
\hline No & 76 & $14.41 \pm 3.84$ & \\
\hline
\end{tabular}

$\mathrm{T} / \mathrm{N}^{\mathrm{a}}, \mathrm{T} / \mathrm{N}$ ratio, IL32 $\alpha / \beta$-actin in tumor (T) divided by IL32 $\alpha / \beta$-actin in non-cancerous tissue $(\mathrm{N})$. ${ }^{\mathrm{b}} \mathrm{P}$-value determined by the Mann-Whitney $\mathrm{U}$ test. ${ }^{\mathrm{C}} \mathrm{P}$-value determined by the Kruskal-Wallis test. HBV, hepatitis B virus; $\mathrm{HCV}$, hepatitis $\mathrm{C}$ virus; AFP, $\alpha$-fetoprotein; SE, standard error.

a water bath for 15 min for antigen retrieval. Goat serum (1\%) was applied to prevent a non-specific reaction. The primary antibody was incubated overnight at $4^{\circ} \mathrm{C}$. An antimouse antibody kit (Jing Mei Biotech, Shanghai, China) was applied and DAB reaction was performed following the protocol. Control IgG antibody was used as a negative control. Histomorphometric analysis was performed by Image-Pro Plus image analysis system (Media Cybernetics, Inc., Rockville, MD, USA). 

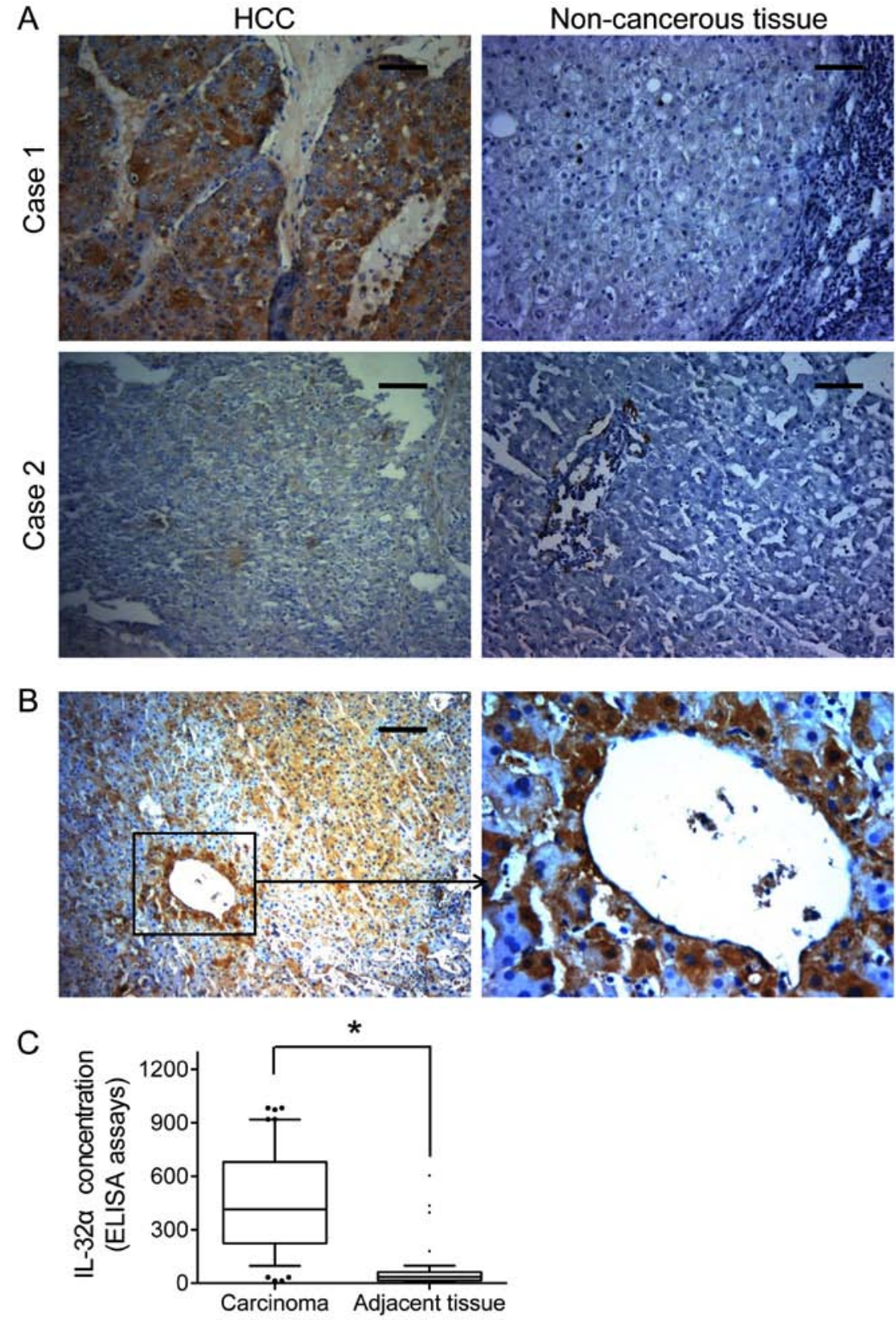

Figure 1. IL-32 $\alpha$ overexpression in HCC correlates with vascular invasion. (A) Representative IHC images of IL-32 $\alpha$ expression in HCC and paired noncancerous tissues. Higher IL-32 $\alpha$ was detected in cancerous tissues. Scale bar, $50 \mu \mathrm{m}$. (B) IHC staining images showed that IL-32 $\alpha$-positive cells were distributed in vessels of tumor tissues. (C) The mean serum concentration of IL-32 $\alpha$ in HCC patients was significantly higher than that in the healthy control group, which was detected by ELISA assays; ${ }^{*} \mathrm{P}<0.05$.

Enzyme-linked immununosorbent assay (ELISA). A sandwich ELISA was designed for the quantification of IL-32 $\alpha$ in human serum. A 96-well microtiter plate was coated overnight at $4^{\circ} \mathrm{C}$ with goat antibody (PAb; R\&D Systems) to IL-32 $\alpha(1 \mu \mathrm{g} / \mathrm{ml}$ in PBS, $100 \mu \mathrm{l} /$ well) and rinsed with PBST. The wells were then coated with $1 \%$ BSA solution in PBS. IL-32 $\alpha$ standard samples were prepared using a serial dilution of a recombinant human IL-32 $\alpha$ solution. Samples were grouped into control and HCC. IL-32 $\alpha$ ELISA was carried out according to the manufacturer's instructions as follows: assay diluent $(80 \mu \mathrm{l})$ was added in duplicate to all wells. Each prepared standard dilution $(20 \mu \mathrm{l})$ was added to samples and incubated at room temperature. Biotin-conjugate $(100 \mu \mathrm{l})$ was added to all wells and incubated at room temperature. Diluted streptavidin-HRP
(100 $\mu \mathrm{l})$ was added to all wells and incubated at room temperature. The enzyme reaction was stopped by quickly pipetting $100 \mu \mathrm{l}$ of stop solution into each well. Absorbance of the reaction product was measured at $490 \mathrm{~nm}$ on an ELISA reader (Molecular Devices, Sunnyvale, CA, USA).

Cell culture and siRNA transfection. HCC cell lines Hu7 and HepG2 were cultured in Dulbecco's modified Eagle's medium (DMEM) supplemented with $100 \mathrm{U} / \mathrm{ml}$ penicillin, $100 \mu \mathrm{g} / \mathrm{ml}$ streptomycin, $25 \mathrm{ng} / \mathrm{ml}$ amphotericin B, and $10 \%$ fetal bovine serum (FBS) (Gibco, Grand Island, NY, USA) at $37^{\circ} \mathrm{C}$ in a humidified incubator with $5 \% \mathrm{CO}_{2}$. For the RNA interference assay, an siRNA for IL-32 $\alpha$ was designed to silence IL-32 $\alpha$ expression in HCC cell lines, Hu7 and HepG2 (Santa Cruz Biotechnology, 
A

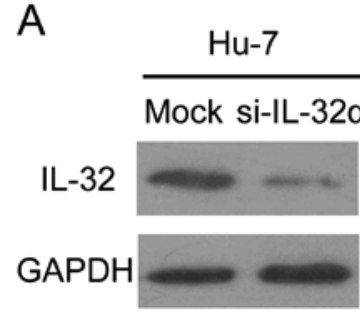

C

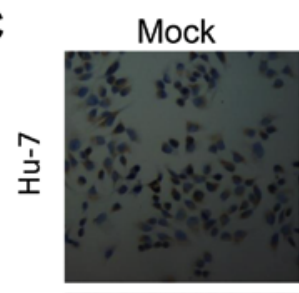

్ㅗㅇ

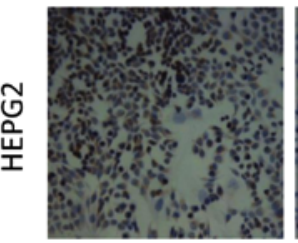

HEPG2

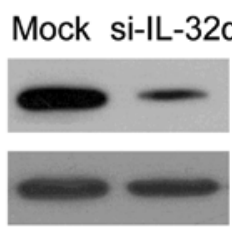

si-IL-32a

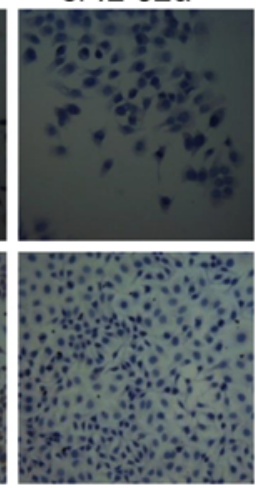

B

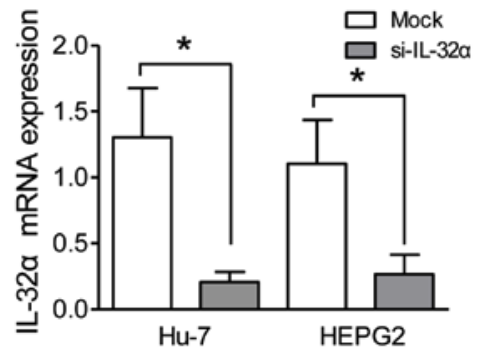

D

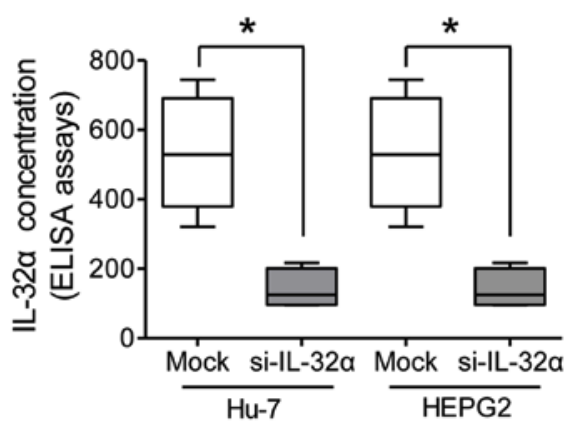

Figure 2. IL-32 $\alpha$ silencing experiment. (A) IL-32 $\alpha$ expression in Hu-7 cells (left) and HEPG2 cells (right) was knocked down with specific shRNA infection, which was detected by immunobloting assays. GAPDH was used as a loading control. (B) IL-32 $\alpha$ mRNA levels in Hu7-si-IL-32 $\alpha$ and mock cells and HEPG2-si-IL-32 $\alpha$ and mock cells were examined by RT-PCR assays. $\beta$-actin was set as a control; ${ }^{~} \mathrm{P}<0.05$. (C) Significantly decreased expression of IL-32 $\alpha$ was observed in Hu7-si-IL-32 $\alpha$ cells compared with mock cells (above) and HEPG2-si-IL-32 $\alpha$ cells compared with mock cells (below), which was detected by cell IHC staining. (D) Similar concentrations of cells (si-IL-32 $\alpha$ and mock cells of Hu7 or HEPG2) were cultured for one day. ELISA assays were also conducted to test IL-32 secretion in the culture medium. Significantly decreased IL-32 $\alpha$ level was observed in Hu7-si-IL-32 $\alpha$ cells; " $P<0.05$.

Santa Cruz, CA, USA). The cells were transfected with $40 \mathrm{nM}$ of siRNA using Lipofectamine ${ }^{\text {TM }}$ LTX (Invitrogen). Silencing efficiency was verified by western blot analysis. Exogenous IL-32 $\alpha$ at a similar concentration $(500 \mathrm{pg} / \mathrm{ml})$ was added to the culture medium for the rescue assay.

Detection of invasion and migration by scratch and Transwell assays. Transfected and control cells were subjected to cell scratch and Transwell invasion assays. For the scratch assay cells were seeded into 6-well plates and cultured until reaching confluence. A wound was created with a sterile pipette tip. The distance was measured by a Nikon DS-5M Camera System mounted on a phase-contrast Leitz microscope. Images of the wound were captured under a phase-contrast microscope at 0,24 and $48 \mathrm{~h}$. For each experiment, 5 visual fields and 2 repeated wells were measured with 3 replications.

For the Transwell assay a 24-well Transwell chamber (8-mm; Millipore) coated with $30 \mu 1$ Matrigel was used for the invasion assay. A 100- $\mu 1$ cell suspension was loaded into the upper Matrigel-coated chamber. DMEM $(600 \mathrm{ml})$ with $10 \%$ FBS was added to the bottom chamber. Cells were then allowed to migrate or invade for $48 \mathrm{~h}$ at $37^{\circ} \mathrm{C}$. The cells in the bottom chamber were fixed in paraformaldehyde and permeabilized in methanol, and then stained with crystal violet dye. Cell images were obtained under a light microscope (Leica DM4000 B; Leica Microsystems, Wetzlar, Germany.

Statistical analysis. The Mann-Whitney U test or KruskalWallis was used for between-group comparisons, where appropriate, and the correlation between the results obtained with the two different analyses was analyzed with the Spearman's test. A paired Student's t-test was used to compare the differences of IL-32- $\alpha$ mRNA and protein expression in tumor tissues and non-cancerous tissues. The correlations of mRNA expression levels were analyzed with Pearson test. $\mathrm{P}<0.05$ was considered statistically significant. All data were analyzed with SPSS 16.0 (SPSS, Inc., Chicago, IL, USA).

\section{Results}

IL-32 $\alpha$ overexpression in HCC correlates with vascular invasion. In order to investigate the expression pattern of IL-32 $\alpha$ in HCC tissue and its prognostic role in HCC patients, we examined the IL-32 $\alpha$ expression levels in $100 \mathrm{HCC}$ samples. IL-32 $\alpha$ expression was found widely elevated in the HCC tissues, as compared with that in the paired non-cancerous tissues (Fig. 1A). Moreover, we analyzed the correlation between IL-32 $\alpha$ serum levels of HCC patients and clinicopathological parameters, including tumor size, virus infection, liver cirrhosis, vascular invasion and metastasis. Statistical results revealed that IL- $32 \alpha$ was much higher in the serum samples of patients with distant metastasis than those without distant metastasis and in patients with vascular invasion (Table I; $\mathrm{P}=0.01$ ). Similarly, IHC staining revealed that high IL-32 $\alpha$ expression was often observed in vessel invasion foci (Fig. 1B). Importantly, HCC patients showed a higher IL-32 $\alpha$ serum concentration than the controls $(571.45 \pm 102.28$ vs. $144.60 \pm 51.172 \mathrm{pg} / \mathrm{ml}, \mathrm{P}=0.007$, Fig. 1C). Taken together, these findings suggest that IL-32 $\alpha$ overexpression can serve as a predictive indicator for distant metastasis and vascular invasion of HCC patients. 
A
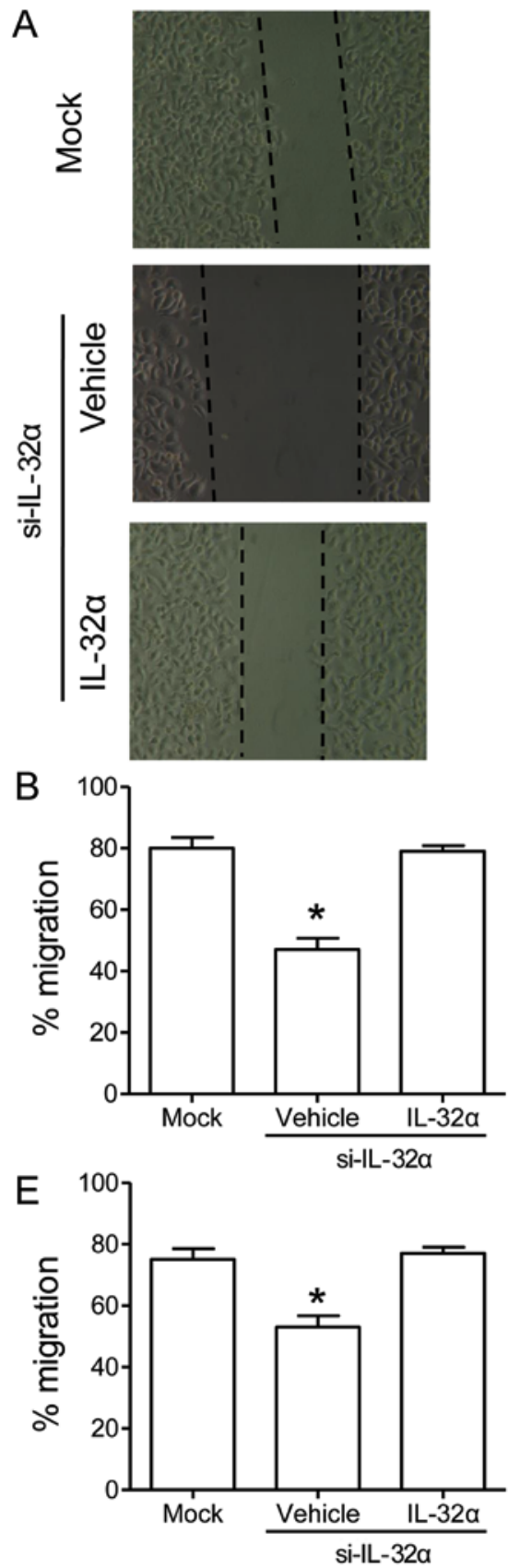

C
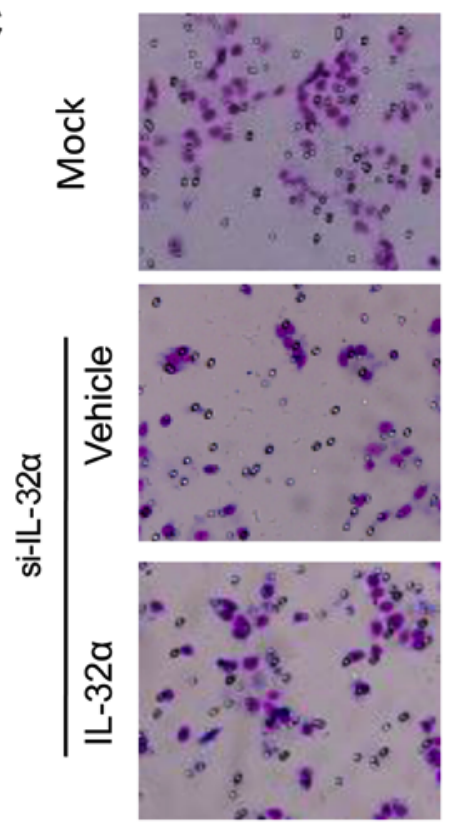

$\mathrm{D}$

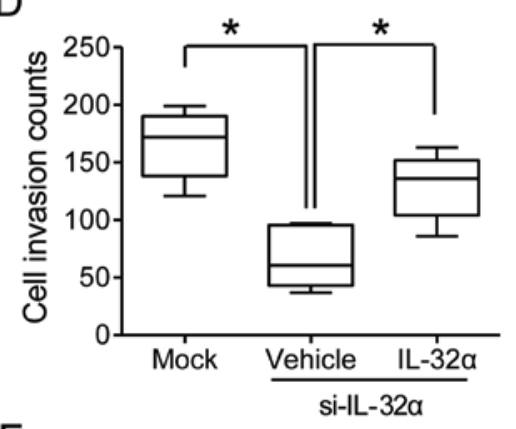

$\mathrm{F}$

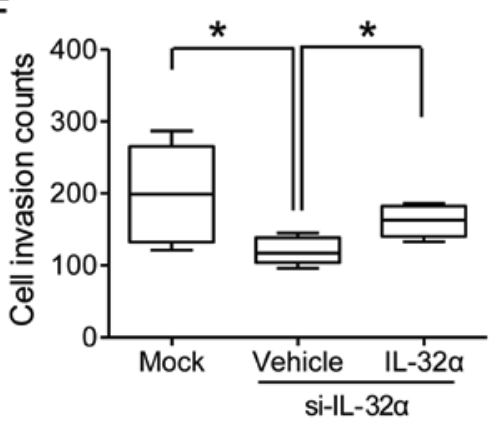

Figure 3. IL-32 $\alpha$ promotes the migration and invasion of HCC cells. (A) Cell scratching assays showed impaired migration ability in the Hu7-si-IL-32 $\alpha$ cells when compared with the mock cells. The top image is performed with mock cells. The bottom 2 images were IL-32 $\alpha$-knockdown cells, and vehicle and exogenous IL-32 $\alpha$ was added for rescue. (B) Transwell invasion assays revealed impaired invasive potential of Hu7-si-IL-32 $\alpha$ cells as compared with that of the Hu7-mock cells; ${ }^{*} \mathrm{P}<0.05$. (C) Transwell invasion assays showed that IL-32 $\alpha$ treatment restored the migration ability of Hu7-si-IL-32 $\alpha$ cells. Exogenous IL-32 $\alpha$ $(500 \mathrm{pg} / \mathrm{ml})$ was added to the culture medium. (D) Exogenous IL-32 $\alpha(500 \mathrm{pg} / \mathrm{ml})$ treatment restored the invasion ability of Hu7-si-IL-32 $\alpha$ cells, which was revealed by Transwell invasion assays; ${ }^{*} \mathrm{P}<0.05$. (E) Cell scratching assays showed sharply reduced migration ability in HepG2-si-IL-32 $\alpha$ cells than mock cells IL-32 $\alpha$ treatment restored migration ability of HepG2-si-IL-32 $\alpha$ cells. Exogenous IL-32 $\alpha$ (500 pg/ml) was added in the culture medium; ${ }^{*} \mathrm{P}<0.05$. (F) Transwell invasion assays revealed the decreased invasive potential of HepG2-si-IL-32 $\alpha$ cells than that of HepG2-mock cells. Exogenous IL-32 $\alpha$ (500 pg/ml) treatment restored invasion ability of HepG2-si-IL-32 $\alpha$ cells; ${ }^{*} \mathrm{P}<0.05$.

IL-32 $\alpha$ promotes migration and invasion of HCC cells. In order to verify the functions of IL-32 $\alpha$ in HCC in vitro, an siRNA of IL-32 $\alpha$ was designed to silence the IL-32 $\alpha$ expression in HCC cell lines, Hu7 and HepG2. The results indicated that IL-32 $\alpha$ was significantly downregulated in the si-IL-32 $\alpha$ treated $\mathrm{Hu} 7$ and $\mathrm{HepG} 2$ cells, as compared with the mock group (Fig. 2A and B). IHC staining assays also confirmed the knockdown of IL-32 $\alpha$ in the HepG2 Hu7 cells (Fig. 2C). As a secreted factor, IL-32 $\alpha$ was also detected in the culture medium, and its concentration in the supernatant was decreased after siRNA knockdown (Fig. 2D). Cell scratch and Transwell invasion assays were carried out in order to examine the cell migration and invasion abilities, respectively. Cell scratch assays revealed that Hu7-si-IL-32 $\alpha$ cells showed sharply reduced migration ability as compared with that of mock cells (Fig. 3A and B; $\mathrm{P}<0.05$ ). For Transwell invasion assays, Hu7-si-IL-32 $\alpha$ cells showed decreased invasive potential than that of Hu7-mock cells (Fig. 3C and D; P<0.05). Similar results 
A
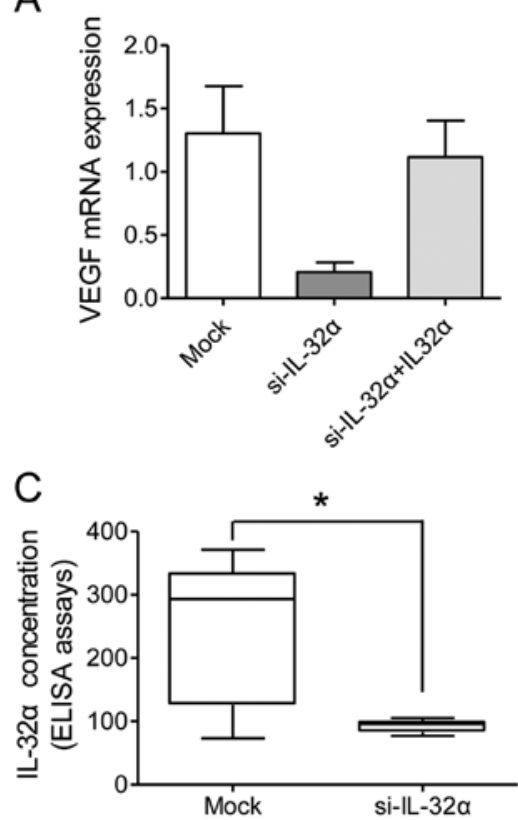

B

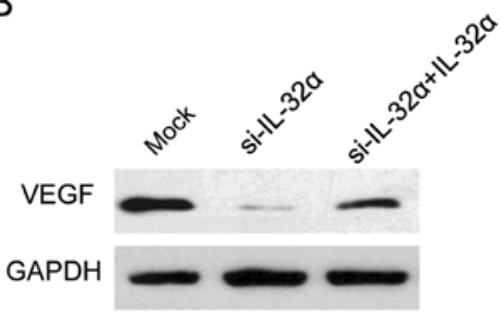

D

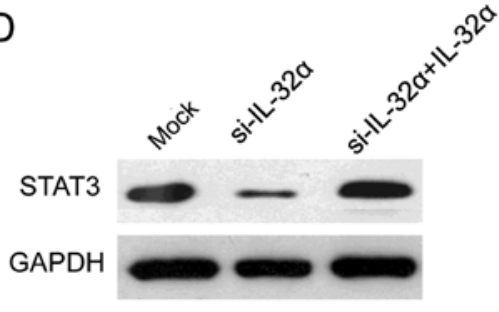

Figure 4. IL-32 $\alpha$ regulates VEGF in HCC cells. (A and B) Significantly reduced VEGF was observed in Hu7-si-IL-32 $\alpha$ cells at the (A) mRNA and (B) protein level. GAPDH was set as a control. (C) ELISA assays showed that IL-32 $\alpha$ silencing in Hu7 cells reduced secretion of VEGF in culture medium; "P $<0.05$. (D) Western blotting showed that STAT3 was significantly reduced in Hu7-si-IL-32 $\alpha$ cells when compared with the mock cells. In addition, exogenous IL-32 $\alpha$ $(500 \mathrm{pg} / \mathrm{ml})$ treatment increased the level of STAT3 in the Hu7-si-IL-32 $\alpha$ cells. GAPDH was used as control.

were also observed in HepG2 cells both in cell scratching and Transwell invasion assays (Fig. 3E and F). To further confirm the role of IL-32 $\alpha$ in regulating cell migration and invasion, exogenous IL-32 $\alpha$ at a similar concentration $(500 \mathrm{pg} / \mathrm{ml})$ was added to the culture medium. Cell scratch assays showed that Hu7-si-IL-32 $\alpha$ cells restored the migration ability with IL-32 $\alpha$ treatment (Fig. 3A and B; P<0.05). For Transwell invasion assays, $\mathrm{Hu} 7-$ si-IL-32 $\alpha$ cells also displayed elevated invasive potential after IL-32 $\alpha$ treatment (Fig. 3C and D; P $<0.05$ ). To sum up, these results indicated that IL- $32 \alpha$ could positively regulate the migration and invasion ability of HCC cells.

$I L-32 \alpha$ regulates VEGF in HCC cells. It has been reported that IL-32 $\alpha$ regulates VEGF levels in breast cancer, which is linked to angiogenesis and tumor invasion $(14,16)$. In order to test whether IL-32 $\alpha$ also modulates VEGF in HCC cells, we examined the level of VEGF after IL-32 $\alpha$ was transiently silenced in the Hu7 and HepG2 cell lines. The present study found that VEGF was significantly reduced after IL- $32 \alpha$ knockdown at both the mRNA level and protein level (Fig. 4A and B). Furthermore, a decreased VEGF level in the culture medium was observed after IL-32 $\alpha$ knockdown (Fig. 4C; $\mathrm{P}<0.05$ ). Collectively, these data showed that VEGF was a downstream response factor of IL-32 $\alpha$ in HCC cells.

Previous reports have revealed that VEGF-STAT3 signaling is important for vascular invasion in a series of tumors $(17,18)$. In the present study, we provided further proofs for the correlation between IL-32 $\alpha$ and VEGF-STAT3 signaling. STAT3 was significantly reduced in the Hu7-si-IL-32 $\alpha$ cells than that noted in the mock cells (Fig. 4D). However, exogenous IL-32 $\alpha$ treatment increased the level of STAT3 in the Hu7-si-IL-32 $\alpha$ cells (Fig. 4D). Taken together, our data revealed that the IL-32 $\alpha /$ VEGF/STAT3 signaling pathway plays an essential role in the vascular invasion in HCC.
IL-32 $\alpha$ is positively correlated with VEGF in both HCC tissues and serum. To further confirm the correlation between IL-32 $\alpha$ and VEGF in HCC, VEGF staining was performed on the HCC tissues and corresponding non-cancerous liver tissues. Our result verified that VEGF expression levels were in accordance with IL-32 $\alpha$ in the HCC tissues, whereas their expression was low in paired non-cancerous tissues (Fig. 5A). Moreover, western blotting of IL-32 $\alpha$ and VEGF were also conducted in 6 cases of $\mathrm{HCC}$ and corresponding non-cancerous liver tissues. A significant correlation was also detected between VEGF and IL-32 $\alpha$ at the relative protein level (VEGF greyscale/GAPDH greyscale and IL-32 $\alpha$ greyscale/GAPDH greyscale) (Fig. 5B). Protein level analysis of the western blotting revealed that IL-32 $\alpha$ and VEGF levels were positively correlated ( $\mathrm{P}<0.05$; Fig. 5C). Furthermore, we investigated IL-32 $\alpha$ and VEGF levels in the HCC patient serum samples. IL- $32 \alpha$ and VEGF protein were positively correlated (Fig. 5D; $\mathrm{P}<0.05$ ). Taken together, these data provide further proof that VEGF may serve as a downstream factor regulated by IL-32 $\alpha$ in HCC.

\section{Discussion}

In the present study, we investigated the expression pattern and functions of IL-32 $\alpha$ in HCC tissues. We demonstrated that elevated IL-32 $\alpha$ in HCC tissues was correlated with the patient tumor stage as well as vascular invasion. We also revealed that silencing of IL-32 $\alpha$ in HCC cells impaired the tumor migration and invasion properties. Importantly, we found that VEGF, an essential factor for cancer growth, invasion and metastasis, served as a downstream response of the IL-32 $\alpha$ signaling pathway in HCC cells.

Increasing evidence has confirmed that inflammation plays a crucial role in liver carcinogenesis. Elevated inflammatory-related cytokines are commonly observed in 

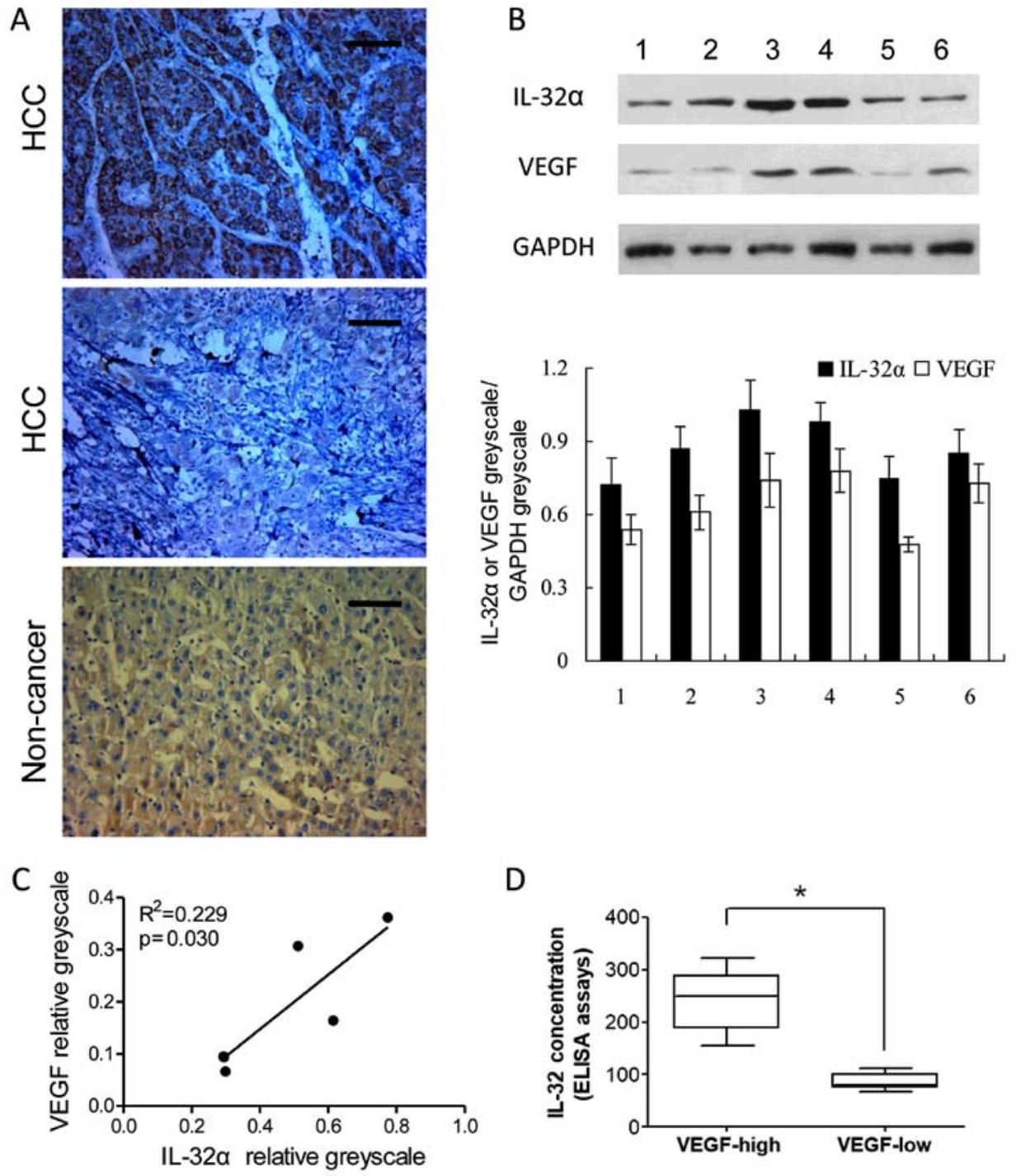

Figure 5. IL-32 $\alpha$ is positively correlated with VEGF in HCC tissue and serum. (A) IHC staining of VEGF expression in HCC and paired non-cancerous tissues, which was consistent with IL-32 $\alpha$. Scale bar, $50 \mu \mathrm{m}$. (B) Western blotting revealed a significant correlation between VEGF and IL-32 $\alpha$ relative protein level in tumor tissues (VEGF/GAPDH and IL-32 $\alpha$ /GAPDH grayscale). GAPDH was used as the control. (C) Grey level analysis revealed that IL-32 $\alpha$ and VEGF levels were positively correlated. (D) ELISA assays showed positive correlation between IL-32 $\alpha$ and VEGF in serum; ${ }^{*} \mathrm{P}<0.05$.

the carcinogenesis and progression of $\operatorname{HCC}(8,19,20)$. IL-32 is known as a pro-inflammatory cytokine since it enhances the production of IL-1 $\beta$ and TNF $\alpha(11,21)$. Higher expression of IL-32 in tumor tissues was observed compared with normal tissue or serum (22). However, different roles are observed with respect to the tumor types among the 6 members of the IL-32 family $(23,24)$. IL-32 $\alpha$ exhibits significant effects in human inflammatory disorders and cancers, and may be involved in the pathogenesis and progression from inflammation to cancer (25).

IL-32 $\alpha$ expression has been observed in a series of tumor tissues, including gastric (26), breast (16) and esophageal cancer (27). Accumulated evidence indicates that IL-32 $\alpha$ participates in cell proliferation and predicts patient overall outcome. IL-32 $\alpha$ knockdown was found to inhibit cell growth and induce intrinsic apoptosis by decreasing phospho-p38, MAPK, NF- $\kappa \mathrm{B}$ and $\mathrm{Bcl}-2$, but increasing pro-apoptotic proteins, p53 and PUMA $(19,28)$. Quite consistent with these studies, we found that IL-32 $\alpha$ was elevated in HCC tissues and associated with patient metastasis as well as vascular invasion, which was reported for the first time. In vitro experiments provided convincing evidence that silencing of IL-32 $\alpha$ in HCC cells sharply reduced the migration and invasion properties of HCC cell lines, which was correlated with VEGF-STAT3 signaling. Further studies will be conducted to investigate the functional role of IL-32 $\alpha$ in HCC progression.

For HCC patients, tumor angiogenesis contributes to a poor therapy response and progression of residual disease (29). Among the tumor angiogenesis regulators, VEGF, an essential growth factor for cancer progression, invasion and metastasis, plays vital roles (30). Previous studies suggest IL-32 as a critical regulator of endothelial cell functions, which possesses angiogenic properties $(31,32)$. Secreted VEGF was also found to be altered along with a change in IL-32 $\alpha$ in breast cancer cells $(14,17)$. Moreover, IL-32 $\alpha$ induced VEGF increased migration and invasion through STAT3 activation, which is a potential target for HCC therapy $(33,34)$. We demonstrated that VEGF is a downstream factor for IL-32 $\alpha$ signaling in 
HCC cells. The detailed mechanism by which IL-32 $\alpha$ regulates VEGF expression requires further investigation.

In conclusion, our findings provide evidence for the clinical relevance and function of IL-32 $\alpha$ in HCC. Elevated IL-32 $\alpha$ in clinical specimens is predictive of tumor metastasis and vascular invasion in HCC patients, which was correlated with VEGF/STAT3 signaling, IL-32 $\alpha$ is a promising therapeutic target for HCC treatment or drug development.

\section{Acknowledgements}

The authors thank the medical and nursing stuff at the Department of Hepatobiliary Surgery at Provincial Hospital Affiliated to Shandong University for providing clinical samples. The present study was supported by the Key Scientific and Medical Project of Shandong Province Health Department (2011QZ016), and the Key Scientific and Medical Project of Taian (2016 NS1076).

\section{References}

1. Ferlay J, Soerjomataram I, Dikshit R, Eser S, Mathers C, Rebelo M, Parkin DM, Forman D and Bray F: Cancer incidence and mortality worldwide: Sources, methods and major patterns in GLOBOCAN 2012. Int J Cancer 136: E359-E386, 2015.

2. Yu SJ: A concise review of updated guidelines regarding the management of hepatocellular carcinoma around the world: 2010-2016. Clin Mol Hepatol 22: 7-17, 2016.

3. Chen W, Zheng R, Baade PD, Zhang S, Zeng H, Bray F, Jemal A, Yu XQ and He J: Cancer statistics in China, 2015. CA Cancer J Clin 66: 115-132, 2016.

4. Poon D, Anderson BO, Chen LT, Tanaka K, Lau WY, Van Cutsem E, Singh H, Chow WC, Ooi LL, Chow P, et al; Asian Oncology Summit: Management of hepatocellular carcinoma in Asia: Consensus statement from the Asian Oncology Summit 2009. Lancet Oncol 10: 1111-1118, 2009.

5. Bellissimo F, Pinzone MR, Cacopardo B and Nunnari G: Diagnostic and therapeutic management of hepatocellular carcinoma. World J Gastroenterol 21: 12003-12021, 2015.

6. Flores A and Marrero JA: Emerging trends in hepatocellular carcinoma: Focus on diagnosis and therapeutics. Clin Med Insights Oncol 8: 71-76, 2014.

7. Petrick JL, Kelly SP, Altekruse SF, McGlynn KA and Rosenberg PS: Future of hepatocellular carcinoma incidence in the united states forecast through 2030. J Clin Oncol 34: 1787-1794, 2016.

8. Han KQ, He XQ, Ma MY, Guo XD, Zhang XM, Chen J, Han H, Zhang WW, Zhu QG, Nian $\mathrm{H}$, et al: Inflammatory microenvironment and expression of chemokines in hepatocellular carcinoma. World J Gastroenterol 21: 4864-4874, 2015.

9. Moschen AR, Fritz T, Clouston AD, Rebhan I, Bauhofer O, Barrie HD, Powell EE, Kim SH, Dinarello CA, Bartenschlager R, et al: Interleukin-32: A new proinflammatory cytokine involved in hepatitis $\mathrm{C}$ virus-related liver inflammation and fibrosis. Hepatology 53: 1819-1829, 2011.

10. Felaco P, Castellani ML, De Lutiis MA, Felaco M, Pandolfi F, Salini V, De Amicis D, Vecchiet J, Tete S, Ciampoli C, et al: IL-32: A newly-discovered proinflammatory cytokine. J Biol Regul Homeost Agents 23: 141-147, 2009.

11. Jeong HJ, Shin SY, Oh HA, Kim MH, Cho JS and Kim HM: IL-32 up-regulation is associated with inflammatory cytokine production in allergic rhinitis. J Pathol 224: 553-563, 2011.

12. Kim S: Interleukin-32 in inflammatory autoimmune diseases. Immune Netw 14: 123-127, 2014.

13. Khawar MB, Abbasi MH and Sheikh N: IL-32: A novel pluripotent inflammatory interleukin, towards gastric inflammation, gastric cancer, and chronic rhino sinusitis. Mediators Inflamm 2016: 8413768, 2016.

14. Park JS, Choi SY, Lee JH, Lee M, Nam ES, Jeong AL, Lee S, Han S, Lee MS, Lim JS, et al: Interleukin-32 $\beta$ stimulates migration of MDA-MB-231 and MCF-7 cells via the VEGFSTAT3 signaling pathway. Cell Oncol 36: 493-503, 2013.
15. Zeng Q, Li S, Zhou Y, Ou W, Cai X, Zhang L, Huang W, Huang L and Wang Q: Interleukin-32 contributes to invasion and metastasis of primary lung adenocarcinoma via NF-kappaB induced matrix metalloproteinases 2 and 9 expression. Cytokine 65: 24-32, 2014.

16. Wang S, Chen F and Tang L: IL-32 promotes breast cancer cell growth and invasiveness. Oncol Lett 9: 305-307, 2015.

17. Ghaffari A, Hoskin V, Szeto A, Hum M, Liaghati N, Nakatsu K, LeBrun D, Madarnas Y, Sengupta S and Elliott BE: A novel role for ezrin in breast cancer angio/lymphangiogenesis. Breast Cancer Res 16: 438, 2014.

18. Liu X, Guo X, Li H, Chen J and Qi X: Src/STAT3 signaling pathways are involved in KAI1-induced downregulation of VEGF-C expression in pancreatic cancer. Mol Med Rep 13: 4774-4778, 2016

19. Galun E: Liver inflammation and cancer: The role of tissue microenvironment in generating the tumor-promoting niche (TPN) in the development of hepatocellular carcinoma. Hepatology 63: 354-356, 2016.

20. Chen Q, Carroll HP and Gadina M: The newest interleukins: Recent additions to the ever-growing cytokine family. Vitam Horm 74: 207-228, 2006.

21. Kim SH, Han SY, Azam T, Yoon DY and Dinarello CA: Interleukin-32: A cytokine and inducer of TNFalpha. Immunity 22: 131-142, 2005.

22. Nishida A, Andoh A, Inatomi O and Fujiyama Y: Interleukin-32 expression in the pancreas. J Biol Chem 284: 17868-17876, 2009.

23. Heinhuis B, Koenders MI, van den Berg WB, Netea MG, Dinarello CA and Joosten LA: Interleukin 32 (IL-32) contains a typical $\alpha$-helix bundle structure that resembles focal adhesion targeting region of focal adhesion kinase-1. J Biol Chem 287: 5733-5743, 2012.

24. Heinhuis B, Netea MG, van den Berg WB, Dinarello CA and Joosten LA: Interleukin-32: A predominantly intracellular proinflammatory mediator that controls cell activation and cell death. Cytokine 60: 321-327, 2012.

25. Ishigami S, Arigami T, Uchikado Y, Setoyama T, Kita Y, Sasaki K, Okumura H, Kurahara H, Kijima Y, Harada A, et al: IL-32 expression is an independent prognostic marker for gastric cancer. Med Oncol 30: 472, 2013.

26. Tsai CY, Wang CS, Tsai MM, Chi HC, Cheng WL, Tseng YH, Chen CY, Lin CD, Wu JI, Wang LH, et al: Interleukin-32 increases human gastric cancer cell invasion associated with tumor progression and metastasis. Clin Cancer Res 20: 2276-2288, 2014.

27. Yousif NG, Al-Amran FG, Hadi N, Lee J and Adrienne J: Expression of IL-32 modulates NF- $\mathrm{KB}$ and p38 MAP kinase pathways in human esophageal cancer. Cytokine 61: 223-227, 2013.

28. Kang YH, Park MY, Yoon DY, Han SR, Lee CI, Ji NY, Myung PK, Lee HG, Kim JW, Yeom YI, et al: Dysregulation of overexpressed IL-32 $\alpha$ in hepatocellular carcinoma suppresses cell growth and induces apoptosis through inactivation of NF- $\kappa \mathrm{B}$ and Bcl-2. Cancer Lett 318: 226-233, 2012.

29. Liu K, Min XL, Peng J, Yang K, Yang L and Zhang XM: The changes of HIF-1 $\alpha$ and VEGF expression after TACE in patients with hepatocellular carcinoma. J Clin Med Res 8: 297-302, 2016.

30. Tsuchiya K, Asahina Y, Matsuda S, Muraoka M, Nakata T, Suzuki Y, Tamaki N, Yasui Y, Suzuki S, Hosokawa T, et al: Changes in plasma vascular endothelial growth factor at 8 weeks after sorafenib administration as predictors of survival for advanced hepatocellular carcinoma. Cancer 120: 229-237, 2014.

31. Nold-Petry CA, Nold MF, Zepp JA, Kim SH, Voelkel NF and Dinarello CA: IL-32-dependent effects of IL-1beta on endothelial cell functions. Proc Natl Acad Sci USA 106: 3883-3888, 2009.

32. Nold-Petry CA, Rudloff I, Baumer Y, Ruvo M, Marasco D, Botti P, Farkas L, Cho SX, Zepp JA, Azam T, et al: IL-32 promotes angiogenesis. J Immunol 192: 589-602, 2014.

33. Hoshida Y, Fuchs BC and Tanabe KK: Prevention of hepatocellular carcinoma: Potential targets, experimental models, and clinical challenges. Curr Cancer Drug Targets 12: 1129-1159, 2012.

34. Welker MW and Trojan J: Antiangiogenic treatment in hepatocellular carcinoma: The balance of efficacy and safety. Cancer Manag Res 5: 337-347, 2013. 